\title{
Estimating The Annual Cost Of Ownership Of A Recreational Horse In Indiana
}

Jonathan M. Furdek, Ph.D., Purdue University Calumet, USA

Susan E. Conners, Ph.D., Purdue University Calumet, USA

\begin{abstract}
A number of studies have attempted to estimate the cost of horse ownership in various States. These studies provided valuable information regarding the types of costs associated with horse ownership and an estimate of a grand average cost. Horse ownership is more complex depending on a variety of factors including location, breed, horse related activities, and potential revenues. In this study, a regression model is developed that provides insights into the factors most relevant to horse ownership costs as well as a more effective model for estimating horse ownership costs in Indiana when compared to an estimation of cost based on a general average.
\end{abstract}

Keywords: Equine Ownership; Cost Analysis; Cost Estimation; Recreational Horses

\section{INTRODUCTION}

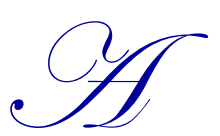

number of studies have attempted to estimate the annual cost of Horse Ownership. Some of those studies are directed at the first time horse owner and identify the responsibilities as well as the costs and benefits derived from annual ownership. The study conducted out of Georgia (Heusner 2011) suggests that the annual cost could range from $\$ 600$ to more than $\$ 4,000$ per year. Based on survey data, Heusner prefers to provide, additionally, a relative breakdown of costs. Generally recognized in most studies are the regular horse maintenance costs of feed, veterinary care, farrier services, bedding, tack, insurance, and medications. Clearly not recognized as annual maintenance costs are the initial investment in purchasing a horse, emergency care, as well as training, travel, machinery, equipment, or competitive fees. Important neglected costs are the costs of boarding, utilities and fuel, repairs and maintenance, and facilities.

Others (Freeman 2004), (Johnson, 1999), (Russell, 1999), typically represented by the study from South Dakota State University (Renelt, 2011) tend to focus on the specific cost categories and on providing specific information regarding each cost category and then attempt to estimate each cost for each category in order to generate an estimate of the typical cost of horse ownership on an annual basis as well as the initial investment costs aside from horse purchases. This information is valuable to first time horse owners, specifying not only the types of costs, in some detail, the time commitment of a horse owner, but also specifics regarding needed corral size, storage space, all the way to including costs for such items as shovels and buckets.

A common theme in many of these studies is that they refer back to the estimates provided annually by the University of Maine (University of Maine Cooperative Extension, 2012). This widely recognized study addresses strategic issues such as selecting a horse, considerations before committing to be a horse owner, determining horse value, and where to purchase a horse. This study is broad and only one fact addresses the annual cost of ownership. The most recent estimate by the University of Maine in 2012, incidentally, which considers only horse maintenance costs of feed, veterinary and farrier services, bedding, training, and maintenance of buildings and pasture, is an average of $\$ 3,876$.

\section{FINDINGS FROM THE 2011 STUDY}

In 2011, an ambitious and comprehensive study of the Indiana Equine industry was undertaken (Conners, 2011). This state-wide study addressed numerous economic and welfare issues in the equine industry, reaching 
participants in the industry from horse racing, horse breeding, equine related businesses, recreational horse owners, competitive horse owners, horse shows, entrepreneurial equine businesses, and equine health. Three separate surveys were involved addressing equine businesses and owners, horse show interest, and horse racing and breeding interests. The data obtained in these surveys was categorized by location, breed, and type of interest in the equine industry. One of the categories was horse ownership for recreational use.

From that study, it was found that although he vast majority of equine were privately held, many of the owners did not perceive their ownership of having any economic consequence, nor did they perceive that their equine involved any business aspect. However, their behavior indicated that they not only incurred costs but also generated revenues. Generally, in Indiana, 60.4 of the equine were for recreational purposes. Recreational horse owners were typically sole owners of these horses $(97.9 \%)$ and most $(75.7 \%)$ boarded their horses rather than maintaining them on their own property, which indicates a significant boarding industry in the State. Most of these horses are boarded with the State of Indiana (98.2\%) with the others boarding horses typically in the adjoining states.

While most of the expenses of horse ownership reported in this study were for horse maintenance (53.4\%), a category that was the focus of many of the earlier studies, there were other categories of expenses, although mentioned in earlier studies, were also significant. These are listed in Table 1 below.

Table 1: Equine Owner Expenses in Indiana, 2010.

\begin{tabular}{|c|c|}
\hline Expense Category & Percentage of Expenses \\
\hline Equine Maintenance & $53.4 \%$ \\
\hline Equine Activities & $18.5 \%$ \\
\hline Investments & $11.6 \%$ \\
\hline Facility Maintenance & $10.3 \%$ \\
\hline Labor & $6.2 \%$ \\
\hline
\end{tabular}

In this study, Equine Maintenance includes the daily expenses found in other studies such as feed, supplements, bedding, stable supplies, veterinary and farrier services, tack and medications, but also included costs of boarding, and utilities so that direct comparisons with previous studies are not concise. Equine activities involved training, travel, fuel and competitive fees. These costs are typically identified with horses involved in competitions and shows. Investments included equine as well as facilities and equipment purchases as well as rentals. Labor costs typically involve any costs paid for a variety of services ranging from horse training, rider training and upkeep of equine services. Labor costs include any benefits and contract payments.

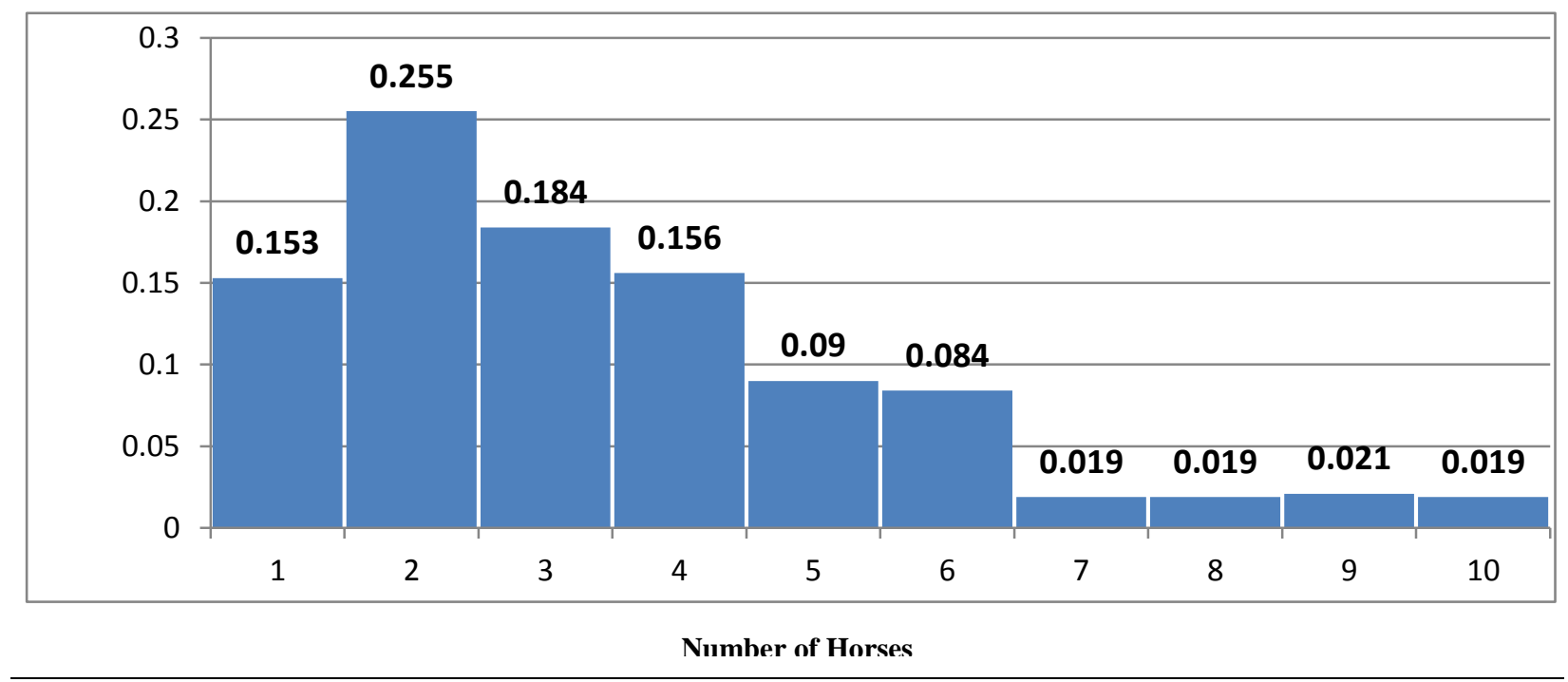

Figure 1: Relative Distribution of the Number of Recreational Horses Owned 
A significant contrast with previous estimates and the findings of this 2011 study is that ownership of a single horse is not typical. While it may serve as instruction for a first time horse owner, these studies do not represent a cost estimate for a typical horse owner in Indiana. The 2011 study found that most owners of recreational horses have several horses. In that study, the average number of horses owned is 4.11. The mode in the study was 2 while the median is 3 . Approximately $3 \%$ of the owners had more than 10 horses. Figure 1 reflects the distribution of horses owned based on the 2011 study.

Although many owners of recreational horses did not report that they generate significant revenues, it is suspected that many board, maintain, and train other horses. Approximately $43 \%$ reported less than $\$ 1,000$ per year in generated revenues, while $5 \%$ generate revenues of $\$ 25,000$ or more per year. However, those recreational horse owners with substantial revenues engaged in horse sales (27\%), yet $40 \%$ had boarding and $26 \%$ had fees from training, rental income, and stud fees. While considering costs for a recreational horse owner, the number of horses is clearly an important factor and revenues generated from horse operations cannot be neglected.

In the 2011 study, the median annual expense reported was $\$ 3,450$ which was substantially (89\%) the cost of horse maintenance.

\section{THE MULTIPLE REGRESSION MODEL}

Considering the Findings from the 2011 study, the following linear model was developed to estimate costs:

$\mathrm{Y}=\quad$ costs of horse ownership which includes the cost of horse maintenance, facility maintenance, labor, horse activities. This cost does not include costs for land, horse purchases, or equipment.

$\mathrm{X} 1=$ number of equine owned.

$\mathrm{X} 2=$ revenues from services provided. Services include stud fees, leasing of horses, boarding horses, training horses, and professional services provided.

$\mathrm{X} 3=$ competitive revenues. These are purses and awards from competitions.

$\mathrm{X} 4=$ zero-one variable for urban area $=1$ and rural area $=0$.

A multiple linear regression model was developed to examine the significance of these variables. It was found that the X2 variable was not significant at any reasonable level, probably due to the wide range of responses in the data set. The model was revised, removing the $\mathrm{X} 2$ variable. The results of the analysis follow.

\begin{tabular}{lllll}
\hline & Coefficients & Standard Error & $t$ Stat & $P$-value \\
\hline Intercept & -1008.052507 & 1091.485142 & -0.923560449 & 0.356545975 \\
X Variable 1 & 2690.507919 & 187.6832318 & 14.33536653 & $5.53982 \mathrm{E}-35$ \\
X Variable 2 & 27.69507575 & 2.129745329 & 13.00393778 & $2.64903 \mathrm{E}-30$ \\
X Variable 3 & 5774.119284 & 1327.531648 & 4.349515352 & $1.9408 \mathrm{E}-05$ \\
\hline
\end{tabular}

Figure 2: Results of the Regression Analysis

Among the various factors considered in this analysis, one interesting factor was the breed of horse. ZeroOne variables were considered for breed to determine if there were any significant differences. This was suspected considering that specific breeds are often related to organizations, competitions or shows. Twelve breed categories were considered: appaloosas, Arabians, draft horses, grade horses, morgans, pintos and paints, quarter horses, standardbreds, thoroughbreds, warmbloods, ponies, donkeys and mules, and other. None of these were significant. On further examination, it was found that a typical recreational horse owner not only held several horses, but also had more than one breed. It appears that breed may have a more significant effect on initial cost than on cost for recreational horse owners.

\section{THE COST ESTIMATION MODEL}

The model derived from this analysis is

$Y=-1008.01+2690.51 X 1+27.70 X 2+5774.12 X 3$ 
As a matter of estimation, a more appropriate estimate may come from this model. For example, a recreational horse owner in an urban area may estimate annual costs, aside from investment costs, as:

$Y=-1008.052507+2690.507919+5774.119284=\$ 7,456.58$

While in a rural area, the cost estimate is:

$Y=-1008.052507+2690.507919=\$ 1,682.46$

The large disparity is likely due to the explicit costs of boarding and maintenance in an urban area that are not regarded in rural areas where pasture and boarding are sunk costs. The significance of competitive awards is simply to recognize that there is a substantial cost to competition. For every dollar of revenue generated from competition, there is a related cost of $\$ 27.70$, on average.

\section{CONCLUSIONS}

Although simple cost estimations may be useful in aiding first time equine owners to identifying the types and magnitudes of costs associated with horse ownership, the model provided here is the next step toward understanding the factors that influence cost and to providing a more precise estimate of cost for the recreational horse entrepreneur. Recognizing that most recreational owners (1) have more than one horse, (2) generate revenues from horse ownership, and (3) have significant cost differences in urban areas compared to rural areas, the model described here is an initial attempt to a more refined approach to estimating horse ownership costs.

\section{AUTHOR INFORMATION}

Jonathan M. Furdek, Ph.D., Purdue University Calumet, Department of Finance \& Economics, 2200 169th Street, Hammond, IN 46323-2094, USA. E-mail: furdek@purduecal.edu (Corresponding author)

Susan E. Conners, Ph.D., Purdue University Calumet, Department of Finance \& Economics, 2200 169th Street, Hammond, IN 46323-2094, USA. E-mail: SConners@purdue.edu

\section{REFERENCES}

1. Conners, S.E., L. Couetil, J.M. Furdek, and M.A. Russell (2011). Indiana Equine Industry Economic Impact and Health Study. Purdue Calumet Equine Program. Hammond, Indiana.

2. Conners, S.E., J.M. Furdek, L. Couetil, G. Preston (2010). Economic Impact of the Indiana Horse Racing and Breeding Industry. Purdue Calumet Equine Program. Hammond, Indiana.

3. Freeman, D.W., O.L. Walker, and B.J. Johnson (2004). "First Time" Horse Ownership: Selecting Horses and Budgeting Horse Interests. Oklahoma Cooperative Extension Service.

4. Heusner, Gary (August 2011). Horse Ownership: Obligations, Costs and Benefits. University of Georgia Cooperative Extension Service. Athens, Goergia.

5. Johnson, E.L., J. Holt, and R.S. Sand (1999). Cost and Responsibilities of Ownership. Horse Industry Handbook. American Youth Horse Council. Pueblo West, Colorado.

6. Russell, M.A. and J.T. Potter (1999). Should I Buy a Horse? Horse Industry Handbook. American Youth Horse Council. Pueblo West, Colorado.

7. University of Maine Cooperative Extension (2012). Guide to First-Time Horse Ownership. Bulletin 1004. University of Maine. www.umaine.edu/publications/1004e . 